\title{
Experimental Investigation of Performance and Emissions in Light Duty Diesel Engine under Different Loads using Diesel-Biodiesel Fuel Blends
}

\author{
A. Rahimi ${ }^{1}$, B. Ghobadian ${ }^{1 *}$, G. Najafi1, M.Montazeri ${ }^{1}$ and H. Zareiforoush ${ }^{2}$ \\ ${ }^{1}$ Mechanical \& Biosystems Engineering Department, Faculty of Agriculture, \\ Tarbiat Modares University, P.O. Box 14115-336, Tehran 14114, Iran. \\ ${ }^{2}$ Mechanization Engineering Department, Faculty of Agricultural Sciences, \\ University of Guilan, P.O.Box 41635-1314, Rasht, Iran. \\ DOI: http://dx.doi.org/10.13005/bbra/1915
}

(Received: 11 September 2015; accepted: 04 November 2015)

\begin{abstract}
In this research, the performance characteristics and exhaust emissions of an air-cooled single-cylinder diesel engine were investigated using different mixtures of biodiesel fuel derived from castor oil. The evaluations were carried out at different engine loads (0, 25, 50, 75 and $100 \%)$ and engine constant speed of $1950 \mathrm{rpm}$. For all of the investigated loads, the generated power by the engine using the different biofuel mixturesincreased.The specific fuel consumptiondecreased for biodiesel blendsin low loads compared to diesel fuel. The lowest emissions of CO pollutant for all of the evaluated mixtures were observed at middle engine loads and the emissions for biodiesel mixtures were lower than those of pure diesel fuel. Emissions of $\mathrm{CO}_{2}$ for all of the evaluated mixtures were lower than those of pure diesel and the highest decrease (8.5\%) was observed for B15 mixture. Compared with pure diesel fuel, the emission of NOx for B5 and B10 mixtures increased insignificantly, whilst the emission decreased for B15 and B20 mixtures. The emissions of unburnedhydrocarbons by the engine decreased by $21 \%$ compared to pure diesel engine.
\end{abstract}

Key words: Biodiesel, performance, pollutant, air-cooled diesel engine

Mechanized agriculture depends on energy, particularly on fossil fuels. Due to increasing growth of mechanization in Iran, utilization of fossil fuels is being increased. Biodiesel,which is chemically an ester, can be used as an alternative fuel for diesel engines. Alternative fuels for diesel engines are becoming increasingly important due to diminishing petroleum reserves and the environmental consequences of exhaust gases from petroleum fuelled engines (fukuda $e t$ al., 2001; Carraretto et al., 2004). This fuel can be obtained from the oil of plants such as maze, sunflower, some oily grains such as castor, peanut,

\footnotetext{
* To whom all correspondence should be addressed. Tel.:+982148292308; Fax: +982148292200;

E-mail: ghobadib@modares.ac.ir; alra_63@yahoo.com
}

wasteedibleoilsand also animalfatswith a methyl factor (Demirbas, 2006).Biodiesel is typically produced through the reaction of a vegetable oil or animal fat with methanol in the presence of a catalyst to yield glycerin and methyl esters (Ghobadian et al.,2007). Nowadays, diesel engines are widely used as power source in many automobiles and off-road vehicles. These engines are of the most important consumers of diesel fuels and their exhaust smoke is one of the factorscausingenvironmental pollution. Currently, due to limitation of fossil fuels and serious environmental problems, search for finding and utilization of alternative fuels is one of themain goals ofresearchers. For this purpose, in recent years several researches have been carried out for studying the feasibility of replacement of diesel 
fuels by biodiesel fuels. The emission of pollutants such as $\mathrm{NOx}, \mathrm{CO}, \mathrm{CO} 2$ and suspended particles from the exhaust of diesel engines magnify the importance of this field of study (Caruana, 2000). The carbon dioxide released from the burning of these fuelsis absorbedbyplantsandtheplants are usedagain forbiodieselproduction. Therefore, carbon dioxide cane be recovered in a naturally closed cycle in the atmosphere (Anonymous, 2010).The growing use of air-cooled single-cylinder diesel engines in widespreadlight duty agricultural machinery (such as two-wheelstractors, different types of mowers, as well as diesel generators, water pumps), coupled withtherelating environmental pollution of such equipment, highlights the necessity of application of alternative fuels in these engines.Hence, the aim of this research was to investigate the performance characteristics and exhaust emissions of an air-cooled single-cylinder diesel engine using different mixtures of biodiesel fuel derived from castor oil.

\section{MATERIALSANDMETHODS}

In this study, production of biodiesel from castor oil was performed based on trance esterification methodusing an ultrasonic device. The ultrasonic device was utilized in a pre-treatment stage to increase the rate of biodiesel production. Different fuel mixtures of diesel and biodiesel (with $0,5,10,15$ and 20 mix percentages) were evaluated. An air-cooled single-cylinder four-cycle diesel engine, which is widely used in agricultural operations, was selected for conducting the experiments. The performance of the engine in terms of fuel consumption, specific fuel consumption and power was investigated under different engine loads and engine speed of 1950 rpm,using a four-stroke engine dynamometer.Fuel consumption was measured according to ASTM D7589 standard.

\section{Specifications of the produced fuel}

Renewable alternative fuels refer to substances with similar characteristics to fossil fuels. Such fuels can effectively replace with fossil fuels. Biodiesel is a methyl or ethyl ester made from vegetable oils or animal fats and can be used as fuel in diesel engines or other thermal systems (Ghobadian and Rahimi, 2004). The biodiesel fuel used in the current research was produced from castor oilin Renewable Energy Laboratory of TarbiatModares University, Tehran, Iran. The gasoil fuel (Gasoil NO. 2) was the common fuel used for diesel engines in Iran. Some important characteristics of the produced biodiesel fuel along with the related standards are presented in Table 1.

\section{Specifications of Dynamometer and tested engine}

In order to measure engine torque, rotational speed and power, A SCHENCK eddycurrent dynamometer was used in the experiments. The dynamometer is able to measure power, rotational speed and torque up to $21 \mathrm{hp}, 10000$ $\mathrm{rpm}$, and $80 \mathrm{~N} . \mathrm{m}$, respectively. The accuracy of the dynamometer was in the range of $0.5-1 \%$ full scale. An overall view of the engine test setup is shown in Fig. 1.

\section{Fuel consumption measurement system}

The system consisted of fuel tank, conjunctions, pipes for fuel transporting, sensor to measure the volume of fuel consumption, thermal transducers of the returned fuel, fuel pressure transducers, fuel pressure gauge and fuel temperature sensor. The measuring accuracy of the system was $\pm 1 \mathrm{cc} / \mathrm{h}$. The system had two digital monitors for displaying fuel temperature in terms of ${ }^{\circ} \mathrm{C}$ and fuel consumption in terms of $\mathrm{cc} / \mathrm{h}$. The system returns the exhaust fuel to the engine combustion chamber after passing the fuel through transducers and cooling units. The system is equipped with fuel tank pressure controller to increase the accuracy of fuel consumption measurement.

\section{Specifications of exhaust emission analyzer}

In order to measure engine emissions, an exhaust emission analyzer (MAHA-MGT5) was used. This device was able to determine the amount of $\mathrm{CO}, \mathrm{CO}$, and $\mathrm{HC}$ using infrared technology. The device could also determine the quantities of $\mathrm{O} 2$ and $\mathrm{NO}_{\mathrm{x}}$ gases using chemical sensors. The measured values could be displayed using the related software of the analyzer (Euro System). The measurement accuracy of the emission analyzer for CO, CO2, HC and NOx particles was $0.06 \%$ (volumetric), 0.5\% (volumetric), $12 \mathrm{ppm}$ and $32 \mathrm{ppm}$, respectively. For measuring the emissions, during each test, after reaching the engine speed to its desired level, the analyzing probe was put into the engine exhaust chamber. Then, the emission indices could be recorded and displayed on the 
monitor. A sample figure representing the test procedure is shown in Fig. 2.

\section{Methods and steps of experiments}

The experiments were carried out during a short-period time and with the aim of comparison of engine emissions and performance characteristics. The comparisons were made between different mixtures of diesel and biodiesel. The controlled variables during the experiments were: applied load to the engine by dynamometer, and type of fuel. The steps of experiments were as follows:

a) Starting up the central control unit of dynamometer

b) Engine warmingup

c) Applying load under engine steady state condition (for each fuel mixture, five loads including 0, 25, 50, 75 and 100\% were applied to engine at constant speed of $1950 \mathrm{rpm}$ )

d) Measurement of torque and calculation of power

e) Measurement of fuel consumption: For this purpose, during each test, signals were sent from volumetric flow sensor to the control system. The fuel measuring device was equipped with fuel temperature control and fuel pressure compensation systems.

f) Measurement of pollutants: The emission sensor was placed on the engine exhaust path and the amounts of emissions were therefore recorded from the system screen.At the end of each test, the emission sensor was cleaned for preventing the effect of exhaust soot on the accuracy of measurements.

\section{RESULTSAND DISCUSSION}

\section{Engine power}

Fig. 3 shows variations of engine power with engine speed using different mixtures of diesel and biodiesel. It was observed that engine power increased with increasing engine load for all of the used fuel mixtures. The highest power was obtained at $100 \%$ engine load. As it can be seen, for all of the fuel mixtures, the values of engine power at low loads are close together. However, when high load were applied, due to increase in air-fuel equivalence ratio, the extra values of oxygen caused to complete combustion with resulted to improve in engine output power (Gumus and Kasifoglu, 2010). Generally, the engine power using different mixtures of biodiesel were close to that of pure diesel fuel and there was no significant difference in this regard.

\section{Specific fuel consumption}

The value of specific fuel consumption (SFC) depends on fuel type (density), fuel consumption rate and engine power on flywheel. SFC is defined as the mass of fuel (in terms of

Table 1. Some important characteristics of the produced biodiesel fuel along with the related standards

\begin{tabular}{lcccc}
\hline Specification & Standard test method & Allowable Range & Biodiesel & Unit \\
\hline Flash point & EN 14214 & 120 (Lowest) & 188.6 & ${ }^{\circ} \mathrm{C}$ \\
Kinematic viscosity & EN 14214 & $3.5-5$ & 13.3 & $\mathrm{~mm}^{2} / \mathrm{s}$ \\
Density & EN 14214 & - & 0.908 & $\mathrm{~g} / \mathrm{cm}^{3}$ \\
Water and sediments & EN 14214 & 0.05 (Highest) & 0.05 & $\%$ vol. \\
Oxidation stability & E 14112 & 8 (Lowest) & 13 & hours \\
\hline
\end{tabular}

Table 2. Specifications of the evaluated engine

\begin{tabular}{ll}
\hline Model & 3LD 510 \\
Manufacturer & Lombardini, Italy \\
NO. Cylinder & 1 \\
Piston stroke & $90 \mathrm{~mm}$ \\
Cylinder diameter & $85 \mathrm{~mm}$ \\
Cylinder volume & $510 \mathrm{~cm}^{3}$ \\
Maximum power (at $3000 \mathrm{rpm})$ & $12.2 \mathrm{hp}(9 \mathrm{~kW})$ \\
Maximum torque (at $1800 \mathrm{rpm})$ & $33 \mathrm{~N} . \mathrm{m}$ \\
\hline
\end{tabular}

gram) which is used for production of $1 \mathrm{kWh}$ real work in engine. This index is calculated by the following equation:

$$
\text { SFC }(g / k W . h)=\frac{M}{P}
$$

Where, $\mathrm{M}$ is the rate of fuel consumption $(\mathrm{g} / \mathrm{h})$ and $\mathrm{P}$ is produced power by engine $(\mathrm{kW})$.

The values of SFC for different mixtures of diesel/biodiesel under different engine loads are 


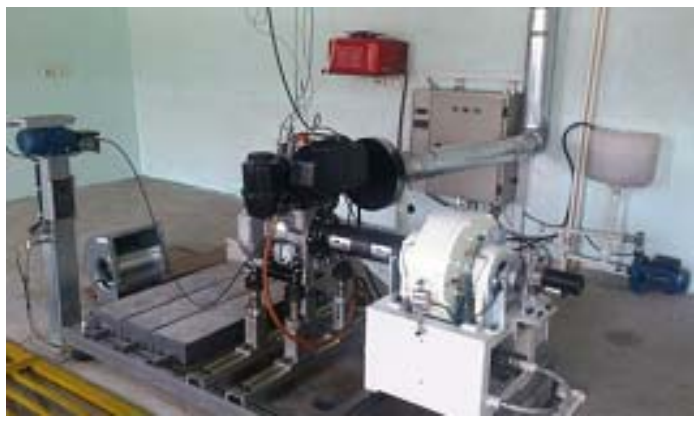

Fig. 1. Engine test set up

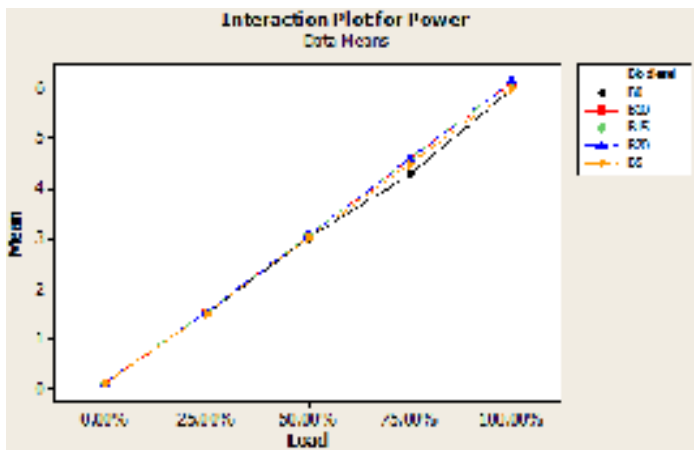

Fig. 3. Variations of engine power with engine loads using different blends of diesel/biodiesel

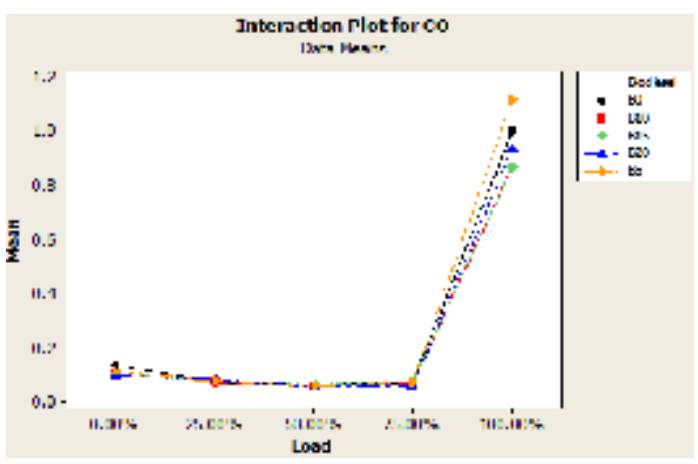

Fig. 5. Variations of $\mathrm{CO}$ emissions with respect to engine load using different blends of diesel/biodiesel

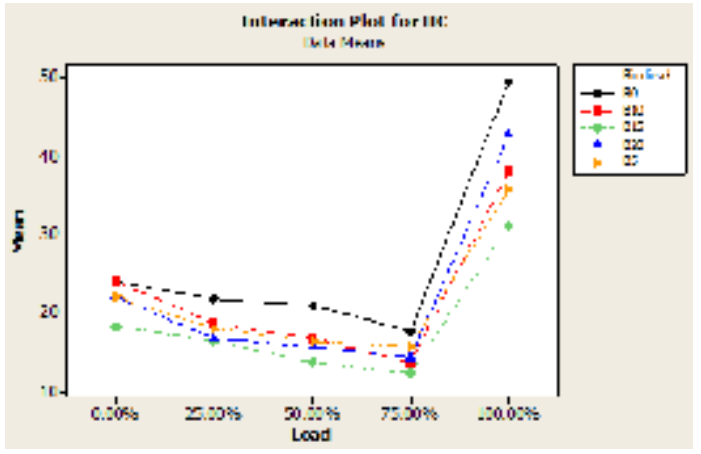

Fig. 6. Variations of HC with respect to engine load for different blends of diesel/biodiesel

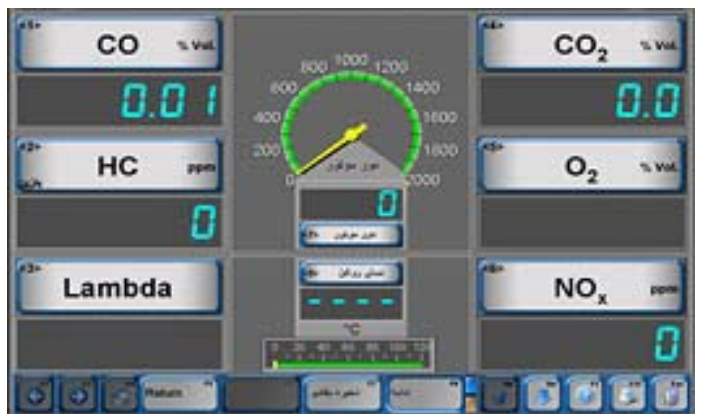

Fig. 2. An overview of the emission analyzer screen

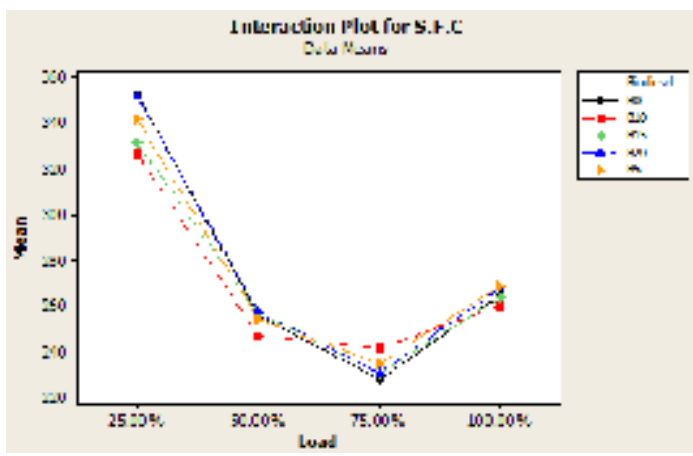

Fig. 4. Variations of SFC with respect to engine load using different blends of diesel/biodiesel

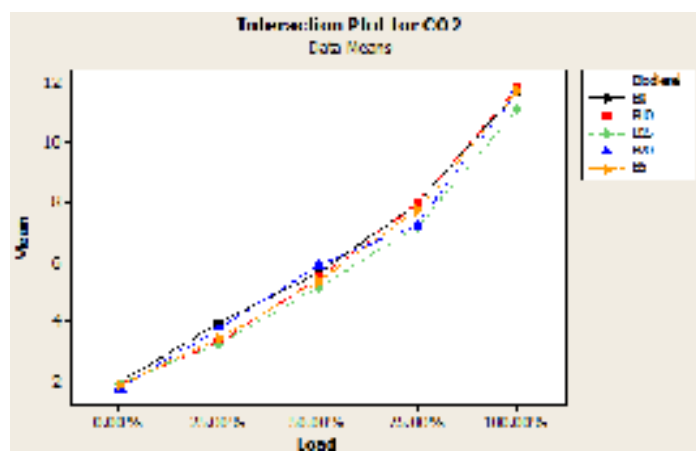

Fig. 6. Variations of $\mathrm{CO}_{2}$ emissions with respect to engine load using different blends of diesel/biodiesel

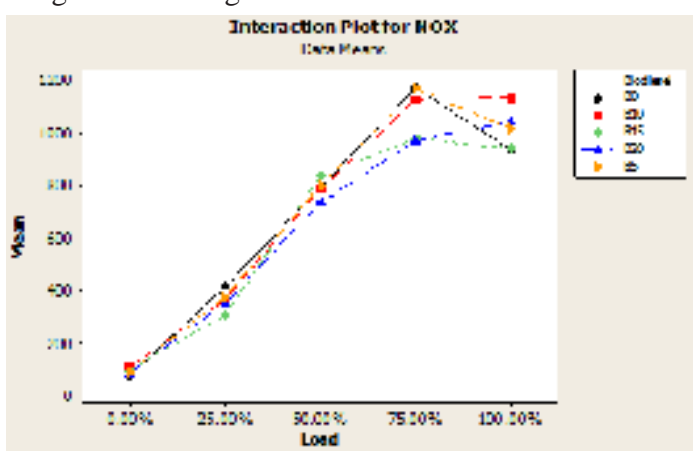

Fig. 7. Variations of NOx with engine load for different blends of diesel/biodiesel 
presented in Fig. 4. For all of the evaluated fuel mixtures, the lowest value of SFC was obtained under medium engine loads. The lowest value of SFC was corresponded to pure diesel fuel. This finding can be justified by low thermal value of pure diesel fuel, low injection quality and low density of the fuel (Ozsezenetal., 2008;Behcet, 2011). Under low loads of engine, the SFC values for biodiesel mixtures were lower than those of pure diesel fuel. The improved combustion of biodiesel fuel due to existence of oxygen and effective combustion time of biodiesel fuels can be the reasons for this result (Behcet, 2011).

\section{Emissions of $\mathrm{CO}$}

The variations of exhaust $\mathrm{CO}$ with different engine loads using different mixtures of diesel/biodiesel is illustrated in Fig. 5. The main reason for existence of $\mathrm{CO}$ among the products of combustion is poor ratio of air-fuel (Abdel-Rahman, 1998). The emissions of CO for biodiesel mixtures were lower than those of pure diesel fuel. Existence of oxygen in biodiesel fuel improves the combustion process and reduces the amount of CO in the exhaustgas (Behcet, 2011). For all of the evaluated fuel mixtures, the amount of CO experienced a decreasing trend from 0 to $75 \%$ engine loads. This trend was then followed by an intensive increase under fuel engine load.

The reason for increase in the amount of CO at engine load of $100 \%$ is rich ratios of air-fuel. When sufficient oxygen is not available for conversion of carbon to carbon dioxide, some of the fuel does not burn completely and consequently, the amount of CO increases in the exhaust gas. Under low loads, the lower local temperatures of the cylinder and rich mixtures of fuels cause to increase in CO formation (Tan et al., 2008). The lowest CO emissions were obtained under medium loads of the tested engine.

\section{Emissions of $\mathrm{CO}_{2}$}

In Fig. 5, the variations of exhaust $\mathrm{CO}_{2}$ versus the engine load for different of diesel/ biodiesel mixtures is presented. For all of the fuel mixtures, the amount of $\mathrm{CO}_{2}$ was increased with increasing engine loads to reach its highest value under full load.

The higher fuel consumption and existence of sufficuient oxygen for fuel burning result in an increase in formation of $\mathrm{CO}_{2}$ at higher loads of engine. Generally, the emissions of $\mathrm{CO}_{2}$ for biodiesel mixtures were lower than those of pure diesel fuel. Increase in the mixture viscosity using biodiesel fuel can result in a reduction in fuel injection angle and available air in the fuel injection area. This factor in turn, increases the local ratio of air-fuel and the lackage of air prevents complete combustion and $\mathrm{CO}_{2}$ formation (GumusandKasifoglu, 2010). Similar trends have been reported by other researchers (Peterson and Hustrulid,1998; Ozsezen etal., 2008).

\section{Emissions of HC}

The variations of exhaust $\mathrm{HC}$ with respect to different loads of engine for different mixtures of diesel/biodiesel is given in Fig. 6. For all of the investigated fuel mixtures, with increasing engine loads from 0 to $75 \%$, the HC value decreased and afterwards, HC showed an ascending trend. The inability to complete oxidation of fuel due to lack of oxygen is the main reason for existence of HC among the products of combustion (Behcet, 2011).

\section{Emissions of NO}

Fig. 7shows the variations of NOx with engine loads using different mixtures of diesel and biodiesel.For all of the studied mixtures, with increasing engine loads, due to increase of engine temperature, the amount of NOx increased. The effective factors on NOx formation include: viscosity of oxygen in the fuel mixture, cylinder maximum pressure, combustion temperature and injection time (Behcet, 2011; Dorado et al., 2003).

As shown in Fig. 7, the amount of NOx produced by biodiesel fuels was lower than that of pure diesel fuel. The short time of pre-mixing phase due to higher cetane number of biodiesel fuels and also lower temperatures of combustion chamber using these fuels can be the reasons for low NOx production at different engine loads (Tan et al.,2008). Similar results have been reported by other researchers (Aydin and Bayindir, 2010).

\section{CONCLUSION}

The following conclusions are derived from the current research:

a) With increasing biodiesel percentage from 5 to $20 \%$ in fuel mixtures, the average difference between the power produced by biodiesel fuels and that of pure diesel fuel increased and the average increase was equal to $1.5 \%$. 
b) For all of the evaluated fuel mixtures, the amount of $\mathrm{CO}_{2}$ emission by biodiesel fuels was lower than that of pure diesel fuel. The highest decrease was attributed to B15 mixture (with 8\% decrease) and the lowest value was corresponded to B10 (with $2 \%$ reduction).

c) The emissions average of $\mathrm{NOx}$ by biodiesel fuels for all of the studied mixturesdecreased compared with pure diesel fuel (with $2.4 \%$. reduction)

d) Comparing with pure diesel fuel, the emissions of CO decreased for all of the biodiesel fuel mixtures and B10 mixture showed the highest decrease with $12.2 \%$ reduction.

e) The emissions of HC for all of the biodiesel fuel mixtures decreased, compared to pure diesel fuel. The B15 mixture had the highest decrease with $32 \%$ reduction.

f) The results revealed that using fuel mixtures produced from castor oil (with 20\%volumetric percentage of biodiesel) can result in an improved working condition for the evaluated engine as well as a remarkable reduction in the engine exhaust emissions.

\section{REFERENCES}

1. A.A. Abdel-Rahman, On the emissions from internal combustion engines:A Review, International Journal of Energy Research 1998; 22: 483-513.

2. Anonymous. Energy report. Available on http:/ /www.window.State.tx.us

3. A.N. Ozsezen, M. Canakci, C. Sayin, Effects of biodiesel from used frying palm oil on the exhaust emissions of an indirect injection (IDI) diesel engine, Energy Fuels 2008; 22: 27962804.

4. Aydin, H. and Bayindir, H., Performance and emission analysis of cottonseed oil methyl ester in a diesel engine. Renewable Energy. 2010; 35: 588-592.
5. Behcet, R., Performance and emission study of waste anchovy fish biodiesel in a diesel engine. Fuel Processing Technology. 2011; 92: 11871194.

6. Carraretto, C., Macor, A., Mirandola, A., Stoppato, A. and Tonon, S., Biodiesel as alternative fuel: Experimental analysis and energetic evaluation. Energy. 2004; 29: 21952211.

7. Caruana, C.M., Pollution control drives new interest in biodiesel. Chemical Engineering Process. 2000; 84:14-18.

8. Demirbas, A., "Progress and Recent Trentds in Biofuels," Progress in Energy and Combustion Science, 2006; 33: 1-18.

9. Dorado, M.P., Ballesteros, E., Arnal, J.M. and Lopez, F.J., Exhaust emissions from a diesel engine fueled with transesterified waste olive oil. Fuel. 2003; 82: 1311-1315.

10. Fukuda H, Kondo A, Noda H. Biodiesel fuel production by transesterification ofoils. Bioscience and Bioengineering 2001; 92: 40516.

11. Ghobadian, B. and Rahimi, H., Biofuels-Past, Peresent and FuturePerspective. the $4^{\text {th }}$ International Iran and Russia Conference. September 8-10, 2004. Shahrekord, Iran, 2004.

12. Ghobadian B, Najafi GH, Rahimi H, Yusaf TF. Future of renewable energies inIran. Renewable and Sustainable Energy Reviews, in press, doi:10.1016/j.rser.2007.11.010.

13. Gumus, M. and Kasifoglu, S., Performance and emission evaluation of a compression ignition engine using a biodiesel (apricot seed kernel oil methyl ester) and its blends with diesel fuel. Biomass and Bioenergy. 2010; 34: 134-139.

14. Prakash, R, Singh, R.K., Murugan, S., Experimental investigation on a diesel engine fueled with bio-oil derived from waste woodebiodiesel emulsions. Energy. 2013; 55: 610-618.

15. Tan, P.-Q., Zhi-Yuan Hu, Di-Ming Lou., Regulated and unregulated emissions from a light-duty diesel engine with different sulfur content fuels. Fuel 2009; 88(6): 1086-1091.

16. Peterson, C. L. and Hustrulid, T., Carbon cycle for rapeseed oil biodiesel fuels. Biomass and Bioenergy.1998; 14: 91-101. 